\begin{tabular}{|c|c|}
\hline Title & Measurement of valence band offsets of InA IN/GaN heterostructures grown by metal-organic vapor phase epitaxy \\
\hline Author(s) & A kazawa, M.; Gao, B.; Hashizume, T.; Hiroki, M.; Y amahata, S.; Shigekawa, N. \\
\hline Citation & $\begin{array}{l}\text { Journal of A pplied Physics, 109(1), } 013703 \\
\text { https://doi.org/10.1063/1.3527058 }\end{array}$ \\
\hline Issue Date & 2011-01-01 \\
\hline Doc URL & http:/hdl .handle.net/2115/44991 \\
\hline Rights & $\begin{array}{l}\text { Copyright } 2011 \text { A merican Institute of Phy sics. This article may be downloaded for personal use only. A ny other use } \\
\text { requires prior permission of the author and the A merican Institute of Physics. The following article appeared in J. A ppl. } \\
\text { Phys. 109, } 013703 \text { (2011) and may be found at https://dx.doi.org/10.1063/1.3527058 }\end{array}$ \\
\hline Type & article \\
\hline File Information & JA P109-1_013703.pdf \\
\hline
\end{tabular}

Instructions for use 


\title{
Measurement of valence-band offsets of InAIN/GaN heterostructures grown by metal-organic vapor phase epitaxy
}

\author{
M. Akazawa, ${ }^{1,2, a)}$ B. Gao, ${ }^{1}$ T. Hashizume, ${ }^{1,2}$ M. Hiroki, ${ }^{3}$ S. Yamahata, ${ }^{3}$ and N. Shigekawa ${ }^{3}$ \\ ${ }_{1}^{1}$ Research Center for Integrated Quantum Electronics, Hokkaido University, Sapporo 060-8628, Japan \\ ${ }^{2}$ JST-CREST, Sanbancho, Chiyoda-ku, Tokyo, 102-0075, Japan \\ ${ }^{3}$ NTT Photonics Laboratories, NTT Corporation, Atsugi, Kanagawa 243-0198, Japan
}

(Received 3 August 2010; accepted 13 November 2010; published online 3 January 2011)

\begin{abstract}
The valence band offsets, $\Delta E_{\mathrm{V}}$, of $\operatorname{In}_{0.17} \mathrm{Al}_{0.83} \mathrm{~N} / \mathrm{GaN}, \operatorname{In}_{0.25} \mathrm{Al}_{0.75} \mathrm{~N} / \mathrm{GaN}$, and $\operatorname{In}_{0.30} \mathrm{Al}_{0.70} \mathrm{~N} / \mathrm{GaN}$ heterostructures grown by metal-organic vapor phase epitaxy were evaluated by using $\mathrm{x}$-ray photoelectron spectroscopy (XPS). The dependence of the energy position and the full width at half maximum of the $\mathrm{Al} 2 p$ spectrum on the exit angle indicated that there was sharp band bending caused by the polarization-induced electric field combined with surface Fermi-level pinning in each ultrathin InAlN layer. The $\Delta E_{\mathrm{V}}$ values evaluated without taking into account band bending indicated large discrepancies from the theoretical estimates for all samples. Erroneous results due to band bending were corrected by applying numerical calculations, which led to acceptable results. The evaluated $\Delta E_{\mathrm{V}}$ values were $0.2 \pm 0.2 \mathrm{eV}$ for $\operatorname{In}_{0.17} \mathrm{Al}_{0.83} \mathrm{~N} / \mathrm{GaN}, \quad 0.1 \pm 0.2 \mathrm{eV}$ for $\operatorname{In}_{0.25} \mathrm{Al}_{0.75} \mathrm{~N} / \mathrm{GaN}$, and $0.0 \pm 0.2 \mathrm{eV}$ for $\operatorname{In}_{0.30} \mathrm{Al}_{0.70} \mathrm{~N} / \mathrm{GaN}$. Despite the large decrease of around $1.0 \mathrm{eV}$ in the band gap of InAIN layers according to the increase in the In molar fraction, the decrease in $\Delta E_{\mathrm{V}}$ was as small as $0.2 \mathrm{eV}$. Therefore, the change in band-gap discontinuity was mainly distributed to that in conduction band offset. (C) 2011 American Institute of Physics.
\end{abstract}

[doi:10.1063/1.3527058]

\section{INTRODUCTION}

Group III-nitrides and their alloys are promising materials that should enable excellent high-power, high-frequency, and optoelectronic devices to be fabricated. Their heterostructures can provide a high-density two-dimensional electron gas (2DEG) with a high saturation velocity in wide-gap semiconductors. Lattice-matched $\quad \operatorname{In}_{\mathrm{x}} \mathrm{Al}_{1-\mathrm{x}} \mathrm{N} \quad(\mathrm{x}$ $=0.17-0.18) / \mathrm{GaN}$ heterostructures without doping can especially provide a 2DEG with high density exceeding 2 $\times 10^{13} \mathrm{~cm}^{-2},{ }^{1-8}$ due to the difference in spontaneous polarization at the interface. ${ }^{9}$ High-performance InAlN/GaN highelectron mobility transistors (HEMTs) have actually been fabricated and reported. ${ }^{2,3,5,10}$ If we expand the scope to include nonlattice-matched InAlN/GaN heterostructures, the band gap, $E_{\mathrm{g}}$, of InAlN can be greatly changed from $6.2 \mathrm{eV}$ (AlN) to $0.67 \mathrm{eV}(\mathrm{InN}) .{ }^{11}$ It has theoretically been predicted that the decrease in the conduction band offset, $\Delta E_{\mathrm{C}}$, according to the increase in the In molar fraction is much larger than decrease in the valence band offset, $\Delta E_{\mathrm{V}}{ }^{12}$ This interface property is useful for barrier-height engineering. The large change in $\Delta E_{\mathrm{C}}$ according to the molar fraction can be verified by confirming the small change in $\Delta E_{\mathrm{V}}$. However, there have been no reports on measuring the change in $\Delta E_{\mathrm{V}}$ by changing the molar fraction.

One of the most useful methods of investigating $\Delta E_{\mathrm{V}}$ is by applying x-ray photoelectron spectroscopy (XPS) to the interface between ultrathin InAlN and GaN layers. However, evaluating $\Delta E_{\mathrm{V}}$ by using XPS is possibly erroneous due to sharp band bending caused by the spontaneous and piezoelectric polarization in ultrathin InAIN layers. In our prelimi-

${ }^{a)}$ Electronic mail: akazawa@rciqe.hokudai.ac.jp. nary work, ${ }^{13}$ the $\Delta E_{\mathrm{V}}$ of lattice-matched $\operatorname{In}_{0.17} \mathrm{Al}_{0.83} \mathrm{~N} / \mathrm{GaN}$ grown by metal-organic vapor phase epitaxy (MOVPE) was evaluated correctly by taking into account band bending due to the polarization-induced electric field combined with surface Fermi-level pinning. In addition to the lattice-matched $\mathrm{In}_{0.17} \mathrm{Al}_{0.83} \mathrm{~N} / \mathrm{GaN}$ heterostructure, the pseudomorphic heterostructures of $\operatorname{In}_{0.25} \mathrm{Al}_{0.75} \mathrm{~N} / \mathrm{GaN}$ and $\operatorname{In}_{0.30} \mathrm{Al}_{0.70} \mathrm{~N} / \mathrm{GaN}$ were also grown and characterized in this work. Erroneous results due to band bending in ultrathin InAlN layers were corrected by applying numerical calculations. Using the measured peak positions of core levels, $E_{\mathrm{CL}}$ 's, without correction, the evaluated $\Delta E_{\mathrm{V}}$ values deviated from the theoretical estimates according to Refs. 11 and 12. However, the corrected values for all the InAlN/GaN interfaces were in good agreement with the theoretical estimates. Despite the large decrease in $E_{\mathrm{g}}$ of the InAlN layers according to the increase in the In molar fraction, small decrease in $\Delta E_{\mathrm{V}}$ were evaluated at the InAlN/GaN interfaces. Therefore the decrease in $E_{\mathrm{g}}$ discontinuity was mostly distributed to that in $\Delta E_{\mathrm{C}}$ at the InAlN/GaN interfaces.

\section{EXPERIMENTAL}

The sample structure used to investigate the interface with XPS is schematically shown in Fig. 1. All the samples were grown on sapphire (0001) substrates by MOVPE without any doping. $\mathrm{In}_{0.17} \mathrm{Al}_{0.83} \mathrm{~N} / \mathrm{GaN}, \mathrm{In}_{0.25} \mathrm{Al}_{0.75} \mathrm{~N} / \mathrm{GaN}$, and $\mathrm{In}_{0.30} \mathrm{Al}_{0.70} \mathrm{~N} / \mathrm{GaN}$ heterostructures with $2.5 \mathrm{~nm}$-thick InAlN layers were prepared. Here, we have defined the photoelectron exit angle, $\theta$, as the elevation angle indicated in Fig. 1. To measure bulk material constants, thick (around $15 \mathrm{~nm}$ ) $\operatorname{In}_{0.17} \mathrm{Al}_{0.83} \mathrm{~N}, \operatorname{In}_{0.25} \mathrm{Al}_{0.75} \mathrm{~N}$, and $\operatorname{In}_{0.30} \mathrm{Al}_{0.70} \mathrm{~N}$ layers on $\mathrm{GaN}$ and a $2 \mu \mathrm{m}$-thick $\mathrm{GaN}$ single layer were also prepared. Tri- 


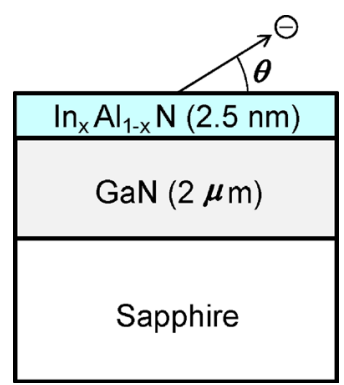

FIG. 1. (Color online) Sample structure for XPS investigations. Definition of exit angle $\theta$ is also shown.

methylgallium was used as a precursor for gallium, trimethylaluminum for aluminum, trimethylindium for indium, and ammonia for nitrogen. The growth temperature was set at $1000{ }^{\circ} \mathrm{C}$ for $\mathrm{GaN}, 820{ }^{\circ} \mathrm{C}$ for $\operatorname{In}_{0.17} \mathrm{Al}_{0.83} \mathrm{~N}, 780{ }^{\circ} \mathrm{C}$ for $\mathrm{In}_{0.25} \mathrm{Al}_{0.75} \mathrm{~N}$, and $730{ }^{\circ} \mathrm{C}$ for $\operatorname{In}_{0.30} \mathrm{Al}_{0.70} \mathrm{~N}$. The details on the growth conditions are described in Ref. 6 . Successful control of the molar fraction in MOVPE growth was confirmed for the thick InAlN layers by using X-ray diffraction. XPS was done by using a monochromated $\mathrm{Al} K \alpha$ x-ray source (1486.6 $\mathrm{eV})$. The binding energy was calibrated by adjusting the peak positions of the $\mathrm{C} 1 \mathrm{~s}$ core levels to $285.0 \mathrm{eV}$ for each sample surface. The morphology of the surfaces was investigated by atomic force microscopy. The surfaces of all the heterostructure samples with the ultrathin InAlN layers were smooth, having monolayer steps, which indicated that the thin InAlN layer had uniform thickness as a result of layerby-layer growth. The XPS data also indicated this state. Surface oxide layers were removed by pretreating them with hydrofluoric (HF) acid.

\section{THEORY OF MEASUREMENT}

A schematic band diagram for the principle of measuring $\Delta E_{\mathrm{V}}$ at the InAlN/GaN interface is outlined in Fig. 2, where $E_{\mathrm{C}}$ is the conduction-band minimum, $E_{\mathrm{V}}$ is the valence-band maximum (VBM), and $E_{\mathrm{F}}$ indicates Fermi level that is set to the origin of binding energy in XPS measurement. In our preliminary work, ${ }^{13}$ we used the In $4 d$ spectrum that overlapped with the Ga $3 d$ and $\mathrm{N} 2 s$ spectra very closely on both sides. The Al $2 p$ spectrum, however, does not overlapped with any other spectra and is therefore more suitable

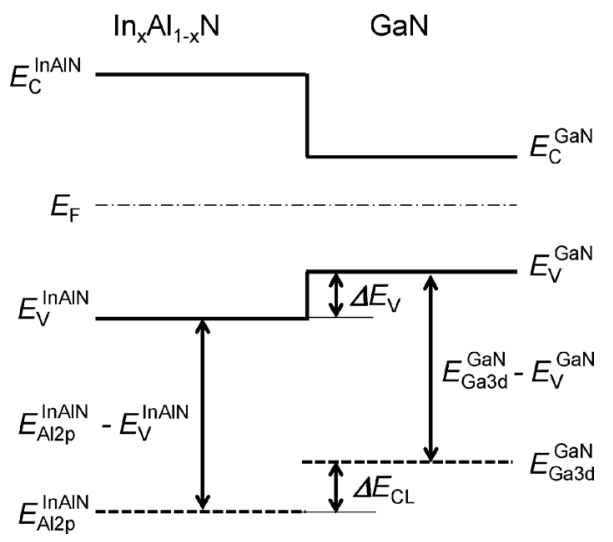

FIG. 2. Schematic band diagram for XPS measurement of $\Delta E_{\mathrm{V}}$. (a)

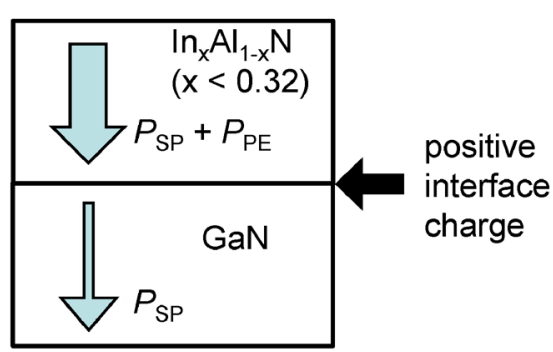

(b)

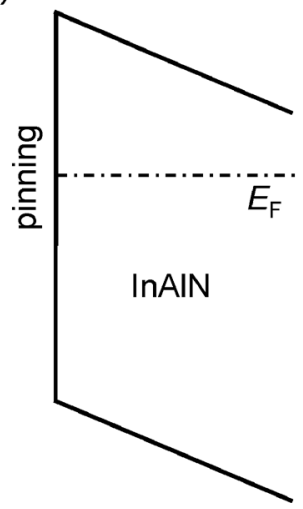

(c)

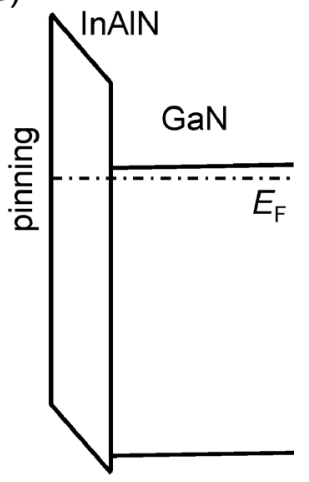

FIG. 3. (Color online) (a) Polarization in pseudomorphic grown wurtzite InAlN/GaN heterostructure with Ga-face polarity. (b) and (c) show possible sharp band bending, in the range of probing depth, schematically for thick and thin InAlN samples.

for the $\Delta E_{\mathrm{V}}$ measurement. We therefore used $\mathrm{Al} 2 p$ in the present work. The $\Delta E_{\mathrm{V}}$ can be estimated from ${ }^{14}$

$$
\Delta E_{\mathrm{V}}=\Delta E_{\mathrm{CL}}+\left(E_{\mathrm{Ga} 3 d}^{\mathrm{GaN}}-E_{\mathrm{V}}^{\mathrm{GaN}}\right)-\left(E_{\mathrm{Al} 2 p}^{\mathrm{InAlN}}-E_{\mathrm{V}}^{\mathrm{InAlN}}\right),
$$

where $\Delta E_{\mathrm{CL}}=\left(E_{\mathrm{Al} 2 p}^{\mathrm{InAlN}}-E_{\mathrm{Ga} 3 d}^{\mathrm{GaN}}\right)$ is the binding energy difference between the measured $\mathrm{Al} 2 p$ and $\mathrm{Ga} 3 d$ core-level spectra of the $\operatorname{InAlN}(2.5 \mathrm{~nm}) / \mathrm{GaN}$ sample. The two $\left(E_{\mathrm{CL}}^{\text {material }}-E_{\mathrm{V}}^{\text {material }}\right)$ terms represent the difference in binding energies between the core level and the VBM for GaN and InAlN as bulk material constants. Here, the $E_{\mathrm{g}}$ of InAlN is larger than that of $\mathrm{GaN}$ in the range of the molar fraction of the prepared samples. ${ }^{11,12}$ The band alignment is therefore type II when $\Delta E_{\mathrm{V}}<0$. This method can, however, be applied to a sample in a nearly flat-band situation, with negligible band bending, at the surface to depths of around $10 \mathrm{~nm}$. This situation will be referred to as a "quasiflat-band" situation after this. If there is sharp band bending at the sample surfaces that affects the XPS data, correction is needed for $E_{\mathrm{CL}}$ 's.

In pseudomorphic grown wurtzite $\operatorname{In}_{\mathrm{x}} \mathrm{Al}_{1-\mathrm{x}} \mathrm{N}$ (x $<0.32) / \mathrm{GaN}$ heterostructures with Ga-face polarity, the sum of spontaneous polarization, $P_{\mathrm{SP}}$, and piezoelectric polarization, $P_{\mathrm{PE}}$, in InAlN is larger than $P_{\mathrm{SP}}$ in GaN as illustrated in Fig. 3(a). ${ }^{7}$ This difference in polarization at the heterointerface produces positive interface charge. Since the Fermi level should be pinned at the InAlN surface, sharp band bending can occur in the InAlN layer. Figures 3(b) and 3(c) show the schematics for the possible surface band bending in the range of the probing depth for samples with thick and ultrathin InAlN layers. Uniform internal electric fields in the outer InAlN layers were calculated for all the samples in the 


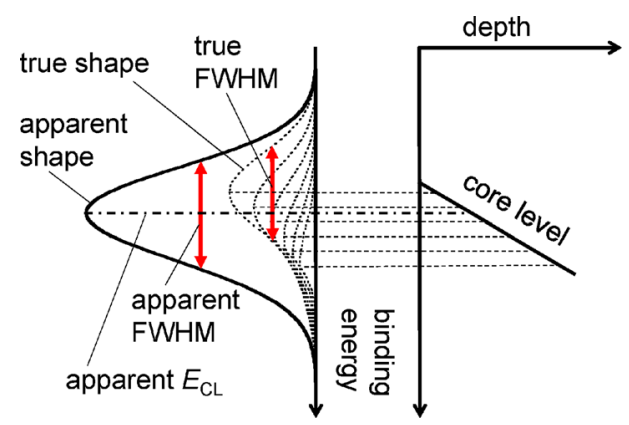

FIG. 4. (Color online) Schematic explaining increases in $E_{\mathrm{CL}}$ and FWHM in apparent spectrum.

range of probing depths and observed surface potentials that will be described later, while the nonuniform electric fields were calculated for GaN layers. Similar results have previously been reported. ${ }^{6-8}$ In XPS measurement, only shallow parts of InAlN layers were probed as shown in Fig. 3(b) for the samples with thick InAIN layers with $2 \mathrm{DEG}$, resulting in no detection of the Ga $3 d$ spectrum from the host $\mathrm{GaN}$ layer. The samples with ultrathin InAIN layers were without 2DEG, which was confirmed by the contactless eddy current method. Consequently, the band bending in the GaN layers of the samples with ultrathin InAIN layers would be observed as a slight tilt of the potential or a nearly flat band in the range of the probing depth. For example, Fig. 3(c) indicates the observed result, for the $\operatorname{In}_{0.17} \mathrm{Al}_{0.83} \mathrm{~N}(2.5 \mathrm{~nm}) / \mathrm{GaN}$ sample, that will be described in Sec. IV. A normally-off type GaN-based HEMT has recently been fabricated by using an ultrathin $\operatorname{In}_{0.17} \mathrm{Al}_{0.83} \mathrm{~N}$ (1 nm)/AIN (1 nm) barrier, ${ }^{10}$ which supports our results because the barrier thickness and the sum of interface charges ${ }^{8}$ are close to those of the $\mathrm{In}_{0.17} \mathrm{Al}_{0.83} \mathrm{~N}(2.5 \mathrm{~nm}) / \mathrm{GaN}$ sample.

In the situations shown in Figs. 3(b) and 3(c), the core levels in the InAlN layer are also bent along with the valence band. As schematically outlined in Fig. 4, the observed spectrum is given by integrating the true spectrum from each depth point along the bent core level. Therefore, sharp band bending results in apparent increases in $E_{\mathrm{CL}}$ and the full width at half maximum (FWHM) of core-level spectra from the InAlN layer. This phenomenon becomes more remarkable by increasing $\theta$ to extend the probing depth. Furthermore, the $E_{\mathrm{CL}}$ of the core-level spectra from the GaN layer increases due to the total potential drop in the InAlN layer for the InAlN/GaN heterostructure sample. With the band bending in Fig. 3(c), $\Delta E_{\mathrm{V}}$ might be evaluated to have a negative value despite the type-I alignment. Therefore, we have to derive the actual $E_{\mathrm{CL}}$ 's by subtracting increases due to band bending so that we can correctly evaluate $\Delta E_{\mathrm{CL}}$.

The sequence of correction for $\Delta E_{\mathrm{V}}$ at the InAlN/GaN heterointerfaces involves three steps

(1) The internal electric field in InAlN is extracted. Assuming a uniform internal electric field in the InAlN layer, the band bending for the entire heterostructure including the GaN layer is calculated by solving the Poisson equation using the measured surface Fermi level, $E_{\text {Fsurf }}$, position as the boundary condition for strong pinning. Then, the apparent $E_{\mathrm{CL}}$ and FWHM due to band bending

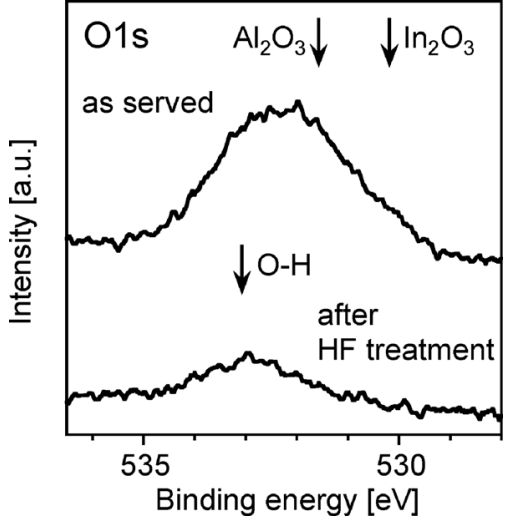

FIG. 5. XPS O $1 s$ spectra observed for $\operatorname{In}_{0.17} \mathrm{Al}_{0.83} \mathrm{~N}$ layer.

are calculated for $\mathrm{Al} 2 p$ and $\mathrm{Ga} 3 d$. This procedure is repeated to find the most suitable internal electric field in InAlN that achieves the apparent $E_{\mathrm{CL}}$ and FWHM observed for $\mathrm{Al} 2 p$ and $\mathrm{Ga} 3 d$.

(2) $E_{\mathrm{CL}}$ values are corrected for $\mathrm{Al} 2 p$ and Ga $3 d$ by subtracting the apparent increases due to band bending to correctly evaluate the $\Delta E_{\mathrm{CL}}$ value.

(3) $\Delta E_{\mathrm{V}}$ is derived using the corrected $\Delta E_{\mathrm{CL}}$ value in Eq. (1).

The details on the calculations to estimate the apparent $E_{\mathrm{CL}}$ and FWHM of core-level spectra due to band bending are as follows. A core-level spectrum as a function of the binding energy, $E$, from a layer of thickness $d$ is given by ${ }^{15}$

$$
I(E)=\int_{0}^{d} I_{0}(E, z) \exp \left(-\frac{z}{\lambda}\right) d z
$$

where $z, \lambda$, and $I_{0}(E, z)$ correspond to the depth from the surface, the escape depth of the photoelectrons, and the spectrum generated at each depth point. Here, to do the calculations within a practical time frame and to avoid heavy computation, the $I_{0}(E, z)$ for one spin orbital is represented by the pseudo-Voigt function given by

$$
\begin{aligned}
V(E, z)= & I_{00}\left[\alpha \exp \left\{-\ln 2 \frac{\left(E-E_{0}\right)^{2}}{(F / 2)^{2}}\right\}\right. \\
& \left.+(1-\alpha) \frac{1}{1+\left\{-\frac{\left(E-E_{0}\right)^{2}}{(F / 2)^{2}}\right\}}\right],
\end{aligned}
$$

where $I_{00}, \alpha, E_{0}$, and $F$ are the intensity, the ratio of the Gaussian function, the binding energy of the core level, and the actual FWHM. When surface band bending is not negligible on the scale of the escape depth of photoelectrons, $E_{0}$ should be treated as a function of depth $z$ to be $E_{0}(\mathrm{z})$. The $F$ was assumed to be a sample dependent constant. The $\alpha$ was fixed to 0.73 for both $\mathrm{Al} 2 p$ and Ga $3 d$ spectra. For Al $2 p$ and $\mathrm{Ga} 3 d$ spectra, $I_{0}(E, z)$ is given by a weighted combination of two pseudo-Voigt-function components taking into account the spin-orbit splitting of $0.41 \mathrm{eV}$ for $\mathrm{Al} 2 p$ and 

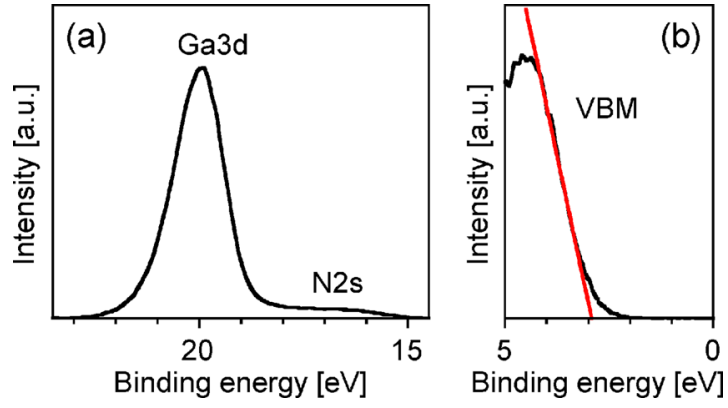

FIG. 6. (Color online) XPS Ga $3 d$ and VBM spectra obtained for thick GaN sample.

$0.44 \mathrm{eV}$ for $\mathrm{Ga} 3 d{ }^{16}$ Furthermore, $\lambda$ can be changed by changing $\theta$ according to

$$
\lambda=\lambda_{0} \sin \theta,
$$

where $\lambda_{0}$ indicates the inelastic mean free path of a photoelectron. The value of $\lambda_{0}$ was calculated using a previously reported equation ${ }^{17,18}$ that was demonstrated to fit the experimental data for several materials including GaN. ${ }^{19}$ The $\lambda_{0}$ of Al $2 p$ spectrum was calculated to be $2.87 \mathrm{~nm}$ for $\operatorname{In}_{0.17} \mathrm{Al}_{0.83} \mathrm{~N}, 2.79 \mathrm{~nm}$ for $\operatorname{In}_{0.25} \mathrm{Al}_{0.75} \mathrm{~N}$, and $2.76 \mathrm{~nm}$ for $\mathrm{In}_{0.30} \mathrm{Al}_{0.70} \mathrm{~N}$. The $\lambda_{0}$ of $\mathrm{Ga} 3 d$ spectrum was calculated to be $2.58 \mathrm{~nm}$ for $\mathrm{GaN}, 2.95 \mathrm{~nm}$ for $\mathrm{In}_{0.17} \mathrm{Al}_{0.83} \mathrm{~N}, 2.88 \mathrm{~nm}$ for $\operatorname{In}_{0.25} \mathrm{Al}_{0.75} \mathrm{~N}$, and $2.84 \mathrm{~nm}$ for $\operatorname{In}_{0.30} \mathrm{Al}_{0.70} \mathrm{~N}$.

\section{RESULTS AND DISCUSSION}

\section{A. Measurement of bulk material constants}

We found that HF treatment efficiently removed oxides from the InAlN and $\mathrm{GaN}$ surfaces. Figure 5 shows the $\mathrm{O} 1 \mathrm{~s}$ spectra before and after $\mathrm{HF}$ treatment for $\mathrm{In}_{0.17} \mathrm{Al}_{0.83} \mathrm{~N}$ at $\theta$ $=45^{\circ} . \operatorname{In}_{2} \mathrm{O}_{3}$ component appear at $530.2 \mathrm{eV}$ (Ref. 20) and that for $\mathrm{Al}_{2} \mathrm{O}_{3}$ appear at $531.6 \mathrm{eV}^{21}$ The spectral intensity at these binding energies drastically decreased after HF treatment leaving only a faint component assigned to $\mathrm{O}-\mathrm{H}$ bonding. ${ }^{22}$ Similar results were also obtained for the $\mathrm{In}_{0.25} \mathrm{Al}_{0.75} \mathrm{~N}, \mathrm{In}_{0.30} \mathrm{Al}_{0.70} \mathrm{~N}$, and $\mathrm{GaN}$ surfaces.

The Ga $3 d$ and VBM spectra observed at $\theta=45^{\circ}$ for the HF-treated thick GaN layer on a sapphire substrate are shown in Fig. 6. The efficiency of HF treatment can also be seen here. The shape of the Ga $3 d$ spectrum was identical to that obtained for the $\mathrm{GaN}(2 \times 2)$ clean surface grown by molecular beam epitaxy, which indicated that the surface was nearly oxide free. The VBM position was determined by linear extrapolation of the low binding energy edge of the valence band spectrum. The value of $\left(E_{\mathrm{Ga} 3 \mathrm{~d}}^{\mathrm{GaN}}-E_{\mathrm{V}}^{\mathrm{GaN}}\right)$ was evalu-
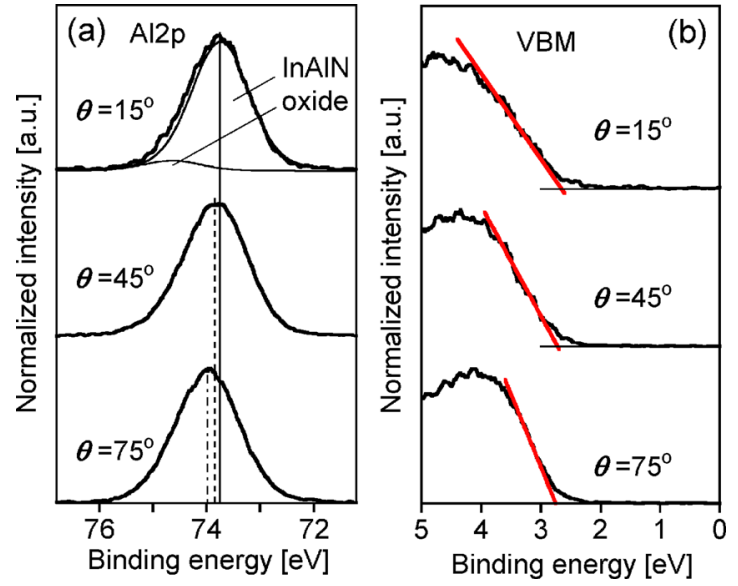

FIG. 7. (Color online) XPS Al $2 p$ and VBM spectra obtained for $\mathrm{In}_{0.17} \mathrm{Al}_{0.83} \mathrm{~N}(14.5 \mathrm{~nm}) / \mathrm{GaN}$ heterostructure.

ated to be $17.10 \pm 0.07 \mathrm{eV}$. The same value was also obtained for the thick $\mathrm{GaN}$ layer on an $\mathrm{SiC}$ substrate.

Figures 7(a) and 7(b) show the Al $2 p$ and VBM spectra obtained at three different $\theta$ 's for the thick $\operatorname{In}_{0.17} \mathrm{Al}_{0.83} \mathrm{~N}$ samples. No oxide components were detected for $\mathrm{Al} 2 p$ spectra at $\theta=45^{\circ}$ or $75^{\circ}$, even though they were detected at the surface sensitive angle of $\theta=15^{\circ}$. It can be seen that the Al $2 p$ spectrum shifts to higher binding energies with the increase in $\theta$, which indicates that there was sharp band bending in the $\operatorname{In}_{0.17} \mathrm{Al}_{0.83} \mathrm{~N}$ layer. We also found that the FWHM of the $\mathrm{Al} 2 p$ spectrum increased with $\theta$. The results are summarized in Table I with the values calculated by assuming an internal electric field of $1.2 \mathrm{MV} / \mathrm{cm}$ in the $\mathrm{In}_{0.17} \mathrm{Al}_{0.83} \mathrm{~N}$ layer. Note that the corrected VBM position in Table $\mathrm{I}$ is close to that reported for $\mathrm{In}_{0.16} \mathrm{Al}_{0.84} \mathrm{~N}^{23}$ Consequently, the bulk material constant $\left(E_{\mathrm{Al} 2 p}^{\text {InAlN }}-E_{\mathrm{V}}^{\text {InAlN }}\right)$ was determined to be $71.10 \pm 0.07 \mathrm{eV}$ for $\operatorname{In}_{0.17} \mathrm{Al}_{0.83} \mathrm{~N}$. The same value was also obtained for the thick $\operatorname{In}_{0.25} \mathrm{Al}_{0.75} \mathrm{~N}$ layer by applying the same method. However, applying the same method to the thick $\operatorname{In}_{0.30} \mathrm{Al}_{0.70} \mathrm{~N}$ layer did not lead to an acceptable result. The thickness needed to investigate the bulk material constant was probably too large for the $\mathrm{In}_{0.30} \mathrm{Al}_{0.70} \mathrm{~N}$ layer to maintain good bulk quality. (Precise evaluation of the critical thickness was beyond the scope of this work.) Therefore, the value of $\left(E_{\mathrm{Al} 2 p}^{\mathrm{InAlN}}-E_{\mathrm{V}}^{\text {InAlN }}\right)$ for $\mathrm{In}_{0.30} \mathrm{Al}_{0.70} \mathrm{~N}$ was extrapolated from the results of two other samples to be $71.10 \mathrm{eV}$.

\section{B. Measurement of band offsets}

To determine $\Delta E_{\mathrm{V}}$, the $\Delta E_{\mathrm{CL}}$ between $\mathrm{Al} 2 p$ and Ga $3 d$ spectra was measured for each heterostructure with the thin

TABLE I. Summary of measured and calculated values of $E_{\mathrm{CL}}$ and FWHM for thick $\operatorname{In}_{0.17} \mathrm{Al}_{0.83} \mathrm{~N}$ layer.

\begin{tabular}{|c|c|c|c|c|c|c|c|c|c|}
\hline \multirow[b]{3}{*}{$\theta$} & \multicolumn{3}{|c|}{$\begin{array}{c}E_{\mathrm{Al} 2 p} \\
(\mathrm{eV})\end{array}$} & \multicolumn{3}{|c|}{$\begin{array}{c}\text { FWHM of Al } 2 p \\
(\mathrm{eV})\end{array}$} & \multicolumn{3}{|c|}{$\begin{array}{l}\text { VBM } \\
(\mathrm{eV})\end{array}$} \\
\hline & \multirow[b]{2}{*}{ Measured } & \multicolumn{2}{|c|}{ Calculated } & \multirow[b]{2}{*}{ Measured } & \multicolumn{2}{|c|}{ Calculated } & \multirow[b]{2}{*}{ Measured } & \multicolumn{2}{|c|}{ Calculated } \\
\hline & & Apparent & Corrected & & Apparent & Corrected & & Apparent & Corrected \\
\hline $15^{\circ}$ & 73.75 & 73.75 & 73.66 & 1.28 & 1.29 & 1.28 & 2.65 & 2.63 & 2.54 \\
\hline $45^{\circ}$ & 73.87 & 73.87 & 73.66 & 1.40 & 1.38 & 1.28 & 2.72 & 2.74 & 2.54 \\
\hline $75^{\circ}$ & 73.98 & 73.95 & 73.66 & 1.42 & 1.44 & 1.28 & 2.75 & 2.75 & 2.54 \\
\hline
\end{tabular}




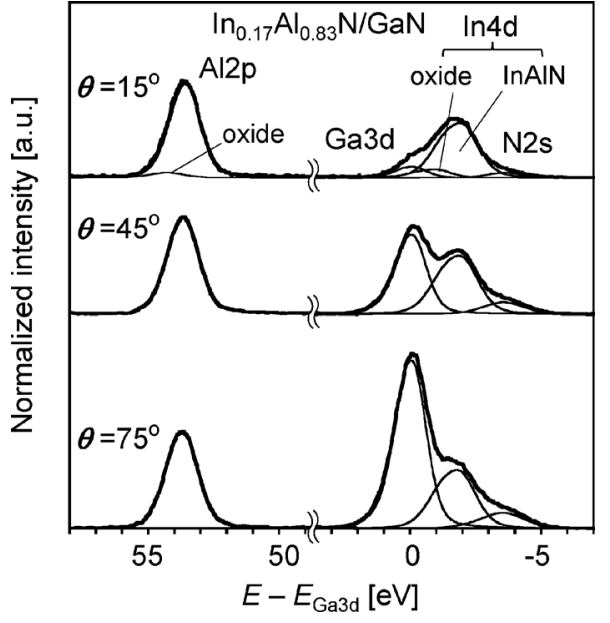

FIG. 8. XPS Al $2 p, \mathrm{Ga} 3 d$, In $4 d$, and $\mathrm{N} 2 s$ core-level spectra obtained for $\operatorname{In}_{0.17} \mathrm{Al}_{0.83} \mathrm{~N}(2.5 \mathrm{~nm}) / \mathrm{GaN}$ heterostructure.

$(2.5 \mathrm{~nm}) \mathrm{InAlN}$ top layer. The spectra we obtained are shown in Fig. 8 for the lattice-matched $\operatorname{In}_{0.17} \mathrm{Al}_{0.83} \mathrm{~N} / \mathrm{GaN}$ heterostructure, in Fig. 9 for the pseudomorphic $\operatorname{In}_{0.25} \mathrm{Al}_{0.75} \mathrm{~N} / \mathrm{GaN}$ heterostructure, and in Fig. 10 for the pseudomorphic $\mathrm{In}_{0.30} \mathrm{Al}_{0.70} \mathrm{~N} / \mathrm{GaN}$ heterostructure. The measured values of $\Delta E_{\mathrm{CL}}$ and $\Delta E_{\mathrm{V}}$ without correction have been summarized in Table II. Using the previously mentioned bulk constant values, all the $\Delta E_{\mathrm{V}}$ values were evaluated to be negative and were not independent of $\theta$. The evaluated $\Delta E_{\mathrm{V}}$ values in Table II are also plotted in Fig. 11 to compare them with the calculated values according to Refs. 11 and 12. The $\Delta E_{\mathrm{V}}$ values without correction deviated from the calculated values and indicated type-II alignments for all the samples despite the prediction of type-I alignments. In addition, the $E_{\mathrm{CL}}$ and FWHM of the Al $2 p$ spectra for $\operatorname{In}_{0.17} \mathrm{Al}_{0.83} \mathrm{~N} / \mathrm{GaN}$ and $\mathrm{In}_{0.25} \mathrm{Al}_{0.75} \mathrm{~N} / \mathrm{GaN}$ interfaces increased with increasing $\theta$ as summarized in Table III. These results indicate that there was sharp band bending in the ultrathin InAlN layers again. Here, the detected internal electric field decreased according to the increase in the In molar fraction. The observed trend is in agreement with the theoretical estimates. ${ }^{9}$

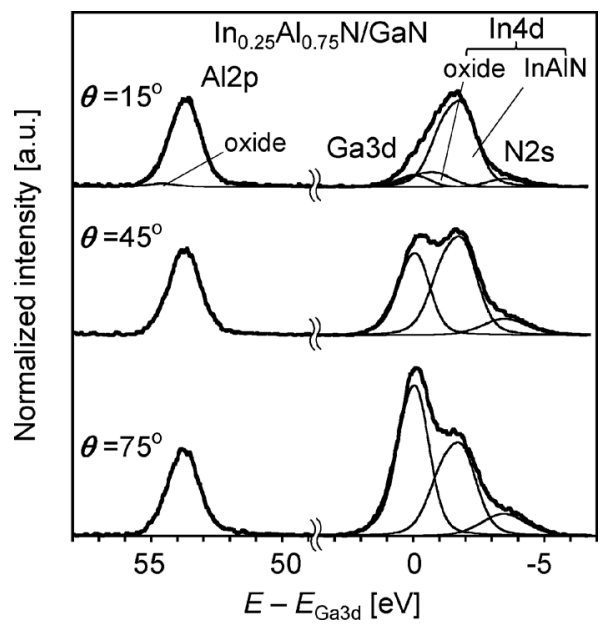

FIG. 9. XPS Al $2 p$, Ga $3 d$, In $4 d$, and $\mathrm{N} 2 s$ core-level spectra obtained for $\mathrm{In}_{0.25} \mathrm{Al}_{0.75} \mathrm{~N}(2.5 \mathrm{~nm}) / \mathrm{GaN}$ heterostructure.

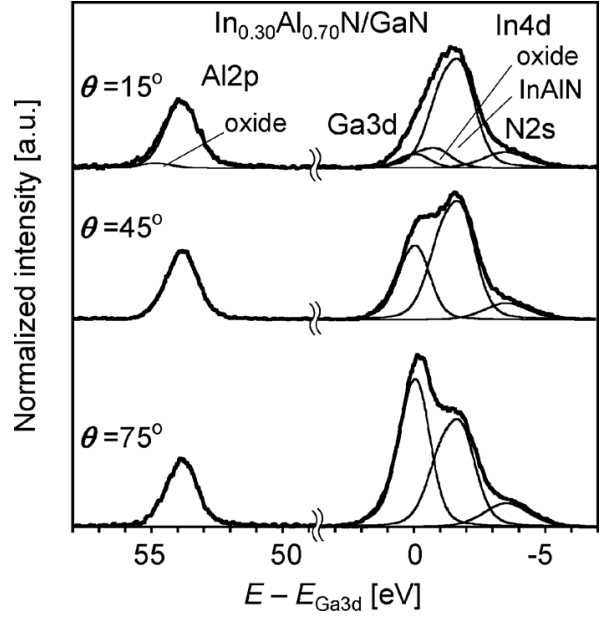

FIG. 10. XPS Al $2 p$, Ga $3 d$, In $4 d$, and $\mathrm{N} 2 s$ core-level spectra obtained for $\mathrm{In}_{0.30} \mathrm{Al}_{0.70} \mathrm{~N}(2.5 \mathrm{~nm}) / \mathrm{GaN}$ heterostructure.

For the $\operatorname{In}_{0.17} \mathrm{Al}_{0.83} \mathrm{~N} / \mathrm{GaN}$ and $\operatorname{In}_{0.25} \mathrm{Al}_{0.75} \mathrm{~N} / \mathrm{GaN}$ samples, increases in the $E_{\mathrm{CL}}$ and FWHM of the $\mathrm{Al} 2 p$ spectra were sufficiently large to extract the internal electric field in the InAlN layers. The previously mentioned calculation reproduced the observed phenomenon for $\mathrm{Al} 2 p$ in the range of experimental error as is also summarized in Table III. The assumed internal electric fields were $3.2 \mathrm{MV} / \mathrm{cm}$ for the $\mathrm{In}_{0.17} \mathrm{Al}_{0.83} \mathrm{~N}$ layer and $2.4 \mathrm{MV} / \mathrm{cm}$ for the $\operatorname{In}_{0.25} \mathrm{Al}_{0.75} \mathrm{~N}$ layer. For Ga $3 d$ spectra, we found that the apparent shift in $E_{\mathrm{Ga} 3 \mathrm{~d}}$ due to band bending in $\mathrm{GaN}$ was a few tens of millielectron volts for the $\mathrm{In}_{0.17} \mathrm{Al}_{0.83} \mathrm{~N} / \mathrm{GaN}$ sample and negligible for the other samples. The corrected $\Delta E_{\mathrm{V}}$ values were $0.2 \mathrm{eV}$ for $\mathrm{In}_{0.17} \mathrm{Al}_{0.83} \mathrm{~N} / \mathrm{GaN}$ and $0.1 \mathrm{eV}$ for $\mathrm{In}_{0.25} \mathrm{Al}_{0.75} \mathrm{~N} / \mathrm{GaN}$, as listed in Table IV with the corrected values of $\Delta E_{\mathrm{CL}}$. The measured band alignments for the quasiflat-band situation using the reported $E_{\mathrm{g}}$ values ${ }^{11}$ are summarized in Figs. 12(a) and 12(b) for the $\operatorname{In}_{0.17} \mathrm{Al}_{0.83} \mathrm{~N} / \mathrm{GaN}$ and $\operatorname{In}_{0.25} \mathrm{Al}_{0.75} \mathrm{~N} / \mathrm{GaN}$ interfaces. Note that the resulting $E_{\mathrm{Fsurf}}$ position for the $\mathrm{In}_{0.17} \mathrm{Al}_{0.83} \mathrm{~N}$ layer in Fig. 12(a) is close to the experimental result previously reported for $\mathrm{In}_{0.16} \mathrm{Al}_{0.84} \mathrm{~N}$.

For the $\operatorname{In}_{0.30} \mathrm{Al}_{0.70} \mathrm{~N} / \mathrm{GaN}$ sample, however, no large increases depending on $\theta$ were observed in either the $E_{\mathrm{Al} 2 p}$ or FWHM as summarized in Table III. Nevertheless, piezoelectric polarization did not completely compensate for spontaneous polarization in the pseudomorphic $\operatorname{In}_{0.30} \mathrm{Al}_{0.70} \mathrm{~N}$ layer

TABLE II. Summary of measured results without correction for InAlN/GaN interfaces.

\begin{tabular}{cccc}
\hline \hline $\mathrm{x}$ & $\theta$ & $\begin{array}{c}\Delta E_{\mathrm{CL}} \\
(\mathrm{eV})\end{array}$ & $\begin{array}{l}\Delta E_{\mathrm{V}} \\
(\mathrm{eV})\end{array}$ \\
\hline \multirow{2}{*}{0.17} & $15^{\circ}$ & 53.61 & -0.4 \\
& $45^{\circ}$ & 53.71 & -0.3 \\
& $75^{\circ}$ & 53.74 & -0.3 \\
0.25 & $15^{\circ}$ & 53.70 & -0.3 \\
& $45^{\circ}$ & 53.75 & -0.3 \\
& $75^{\circ}$ & 53.78 & -0.2 \\
0.30 & $15^{\circ}$ & 53.85 & -0.2 \\
& $45^{\circ}$ & 53.85 & -0.2 \\
& $75^{\circ}$ & 53.85 & -0.2 \\
\hline \hline
\end{tabular}




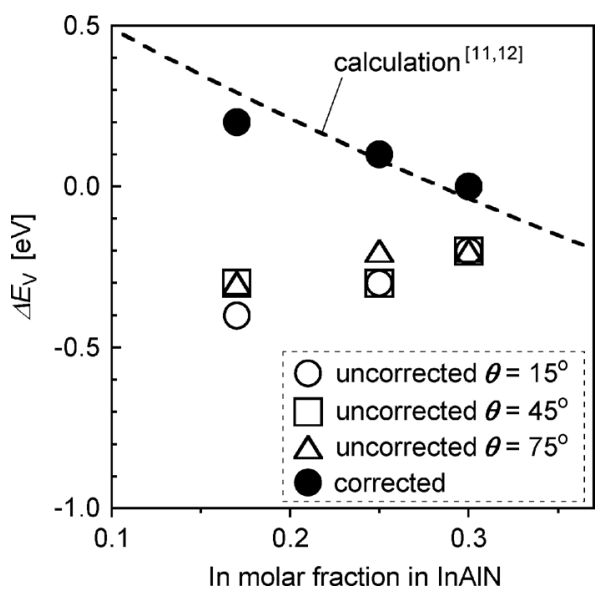

FIG. 11. Measured $\Delta E_{\mathrm{V}}$ values with and without correction vs. In molar fraction in comparison with theoretical calculation according to Refs. 11 and 12.

according to the theoretical estimate in Ref. 9. Therefore, it is likely there was an internal electric field in the $\mathrm{In}_{0.30} \mathrm{Al}_{0.70} \mathrm{~N}$ layer. The numerical calculations indicated that the increases in apparent $E_{\mathrm{Al} 2 p}$ and FWHM were negligible within experimental error with internal electric fields up to $1.2 \mathrm{MV} / \mathrm{cm}$ in the $\operatorname{In}_{0.30} \mathrm{Al}_{0.70} \mathrm{~N}$ layer. This maximum value for the electric field is in good agreement with the theoretical estimates in Ref. 9 and leads to the correction of $\Delta E_{\mathrm{V}}$ at the $\mathrm{In}_{0.30} \mathrm{Al}_{0.70} \mathrm{~N} / \mathrm{GaN}$ interface to be $0.0 \mathrm{eV}$ as shown in Fig. 12(c) and Table IV. The rationality of this correction is given by resultant $E_{\mathrm{Fsurf}}$ positions as follows.

The Fermi-level stabilization energy, $E_{\mathrm{Fstab}}$, has been reported to be an energy position where $E_{\mathrm{F}}$ stabilizes for sufficiently high damage density. ${ }^{24}$ The $E_{\mathrm{Fstab}}$ lies at $4.9 \mathrm{eV}$ from the vacuum level in all semiconductors. ${ }^{24}$ This energy level can therefore be used as a common benchmark point for $E_{\text {Fsurf }}$ position. In the quasiflat-band situation of InAlN/GaN heterointerface, the value of $\left(E_{\mathrm{Fsurf}}-E_{\mathrm{Fstab}}\right)$ should be identical for both InAlN and GaN layers. The measured values of $\left(E_{\mathrm{Fsurf}}-E_{\mathrm{Fstab}}\right)$ are summarized in Table V. Note that there was $0.2 \mathrm{eV}$ of difference in $\left(E_{\mathrm{Fsurf}}-E_{\mathrm{Fstab}}\right)$ between $\mathrm{In}_{0.3} \mathrm{Al}_{0.7} \mathrm{~N}$ and $\mathrm{GaN}$ without correction for the $\mathrm{In}_{0.3} \mathrm{Al}_{0.7} \mathrm{~N} / \mathrm{GaN}$ interface, whereas no such differences were
TABLE IV. Summary of corrected $\Delta E_{\mathrm{CL}}$ and $\Delta E_{\mathrm{V}}$ values for InAlN/GaN interfaces.

\begin{tabular}{ccc}
\hline \hline $\mathrm{x}$ & $\begin{array}{c}\Delta E_{\mathrm{CL}} \\
(\mathrm{eV})\end{array}$ & $\begin{array}{l}\Delta E_{\mathrm{V}} \\
(\mathrm{eV})\end{array}$ \\
\hline 0.17 & 54.20 & 0.2 \\
0.25 & 54.13 & 0.1 \\
0.30 & 54.04 & 0.0 \\
\hline \hline
\end{tabular}

seen in the corrected data for the $\operatorname{In}_{0.17} \mathrm{Al}_{0.83} \mathrm{~N} / \mathrm{GaN}$ and $\mathrm{In}_{0.25} \mathrm{Al}_{0.75} \mathrm{~N} / \mathrm{GaN}$ interfaces. The difference in uncorrected values of $\left(E_{\mathrm{Fsurf}}-E_{\mathrm{Fstab}}\right)$ for the $\operatorname{In}_{0.30} \mathrm{Al}_{0.70} \mathrm{~N} / \mathrm{GaN}$ interface must have been caused by the internal electric field. After correction assuming $1.2 \mathrm{MV} / \mathrm{cm}$ in $\operatorname{In}_{0.30} \mathrm{Al}_{0.70} \mathrm{~N}$, the difference disappeared, as seen in Table V. Moreover, the dispersion of $E_{\mathrm{Fsurf}}$ for the same surface pretreatment for InAlN/ $\mathrm{GaN}$ heterostructures should be discussed. Even though the $E_{\text {Fsurf }}$ positions of the HF-treated samples may disperse statistically depending on the sample, the dispersion for the same treatment is likely to be within a few $0.1 \mathrm{eV}$. As can be seen from Table $\mathrm{V}$, the $\left(E_{\mathrm{Fsurf}}-E_{\mathrm{Fstab}}\right)$ was evaluated to be $0.0 \mathrm{eV}$ for the $\mathrm{In}_{0.17} \mathrm{Al}_{0.83} \mathrm{~N} / \mathrm{GaN}$ interface and $-0.2 \mathrm{eV}$ for the $\mathrm{In}_{0.25} \mathrm{Al}_{0.75} \mathrm{~N} / \mathrm{GaN}$ interface. For the $\mathrm{In}_{0.3} \mathrm{Al}_{0.7} \mathrm{~N} / \mathrm{GaN}$ sample, however, the value was estimated to be $0.3 \mathrm{eV}$ for the GaN surface without correction resulting in a wide dispersion of $0.5 \mathrm{eV}$. This discrepancy dependent on the sample is not acceptable. After correction assuming $1.2 \mathrm{MV} / \mathrm{cm}$ in $\mathrm{In}_{0.30} \mathrm{Al}_{0.70} \mathrm{~N}$, the dispersion width reduced to be an acceptable value of $0.2 \mathrm{eV}$. Therefore, correction resulting in a $\Delta E_{\mathrm{V}}$ value of $0.0 \mathrm{eV}$ for $\mathrm{In}_{0.30} \mathrm{Al}_{0.70} \mathrm{~N}$ was appropriate.

As can be seen in Fig. 11, the corrected $\Delta E_{\mathrm{V}}$ values are in good agreement with the calculated values for all the interfaces. The experimental error was evaluated by considering the fitting errors and the discrepancy between repeated measurements to be $\pm 40 \mathrm{meV}$ for $\Delta E_{\mathrm{CL}}$ and $\pm 70 \mathrm{meV}$ for the two $\left(E_{\mathrm{CL}}-E_{\mathrm{V}}\right)$ components in Eq. (1). Without correction by using numerical calculations, the total error for $\Delta E_{\mathrm{V}}$ is $\pm 180 \mathrm{meV}$. Fitting by numerical calculations introduces an additional error of $\pm 60 \mathrm{meV}$ resulting in a total error of $\pm 240 \mathrm{meV}$. Since the final results were approximated values in units of $0.1 \mathrm{eV}$, the errors in both cases should be $\pm 0.2 \mathrm{eV}$,

TABLE III. Comparison of measured and calculated values for $E_{\mathrm{Al} 2 p}$ and FWHM of $\mathrm{Al} 2 p$ spectra from ultrathin InAlN layers on GaN.

\begin{tabular}{|c|c|c|c|c|c|c|c|}
\hline \multirow[b]{3}{*}{$\mathrm{x}$} & \multirow[b]{3}{*}{$\theta$} & \multicolumn{3}{|c|}{$\begin{array}{c}E_{\mathrm{Al} 2 p} \\
(\mathrm{eV})\end{array}$} & \multicolumn{3}{|c|}{$\begin{array}{c}\text { FWHM of Al } 2 p \\
(\mathrm{eV})\end{array}$} \\
\hline & & \multirow[b]{2}{*}{ Measured } & \multicolumn{2}{|c|}{ Calculated } & \multirow[b]{2}{*}{ Measured } & \multicolumn{2}{|c|}{ Calculated } \\
\hline & & & Apparent & Corrected & & Apparent & Corrected \\
\hline \multirow[t]{3}{*}{0.17} & $15^{\circ}$ & 74.01 & 74.00 & 73.80 & 1.36 & 1.35 & 1.28 \\
\hline & $45^{\circ}$ & 74.11 & 74.11 & 73.80 & 1.40 & 1.40 & 1.28 \\
\hline & $75^{\circ}$ & 74.13 & 74.14 & 73.80 & 1.41 & 1.41 & 1.28 \\
\hline \multirow[t]{3}{*}{0.25} & $15^{\circ}$ & 73.69 & 73.68 & 73.52 & 1.40 & 1.41 & 1.36 \\
\hline & $45^{\circ}$ & 73.74 & 73.76 & 73.52 & 1.43 & 1.43 & 1.36 \\
\hline & $75^{\circ}$ & 73.77 & 73.77 & 73.52 & 1.44 & 1.44 & 1.36 \\
\hline \multirow[t]{3}{*}{0.30} & $15^{\circ}$ & 73.70 & 73.69 & 73.61 & 1.42 & 1.42 & 1.41 \\
\hline & $45^{\circ}$ & 73.72 & 73.73 & 73.61 & 1.42 & 1.42 & 1.41 \\
\hline & $75^{\circ}$ & 73.73 & 73.74 & 73.61 & 1.42 & 1.42 & 1.41 \\
\hline
\end{tabular}


(a)

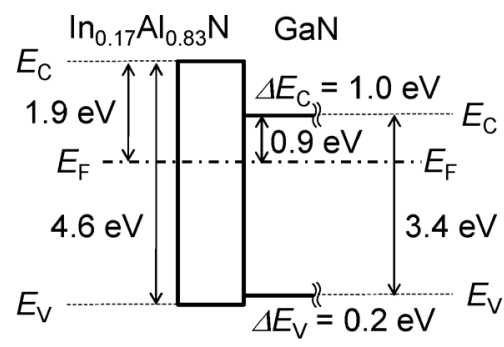

(b)

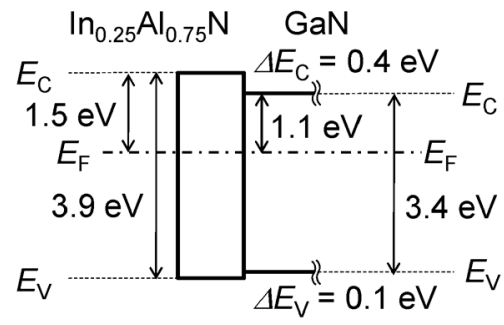

(c)

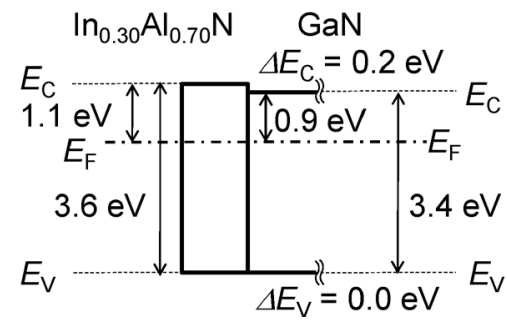

FIG. 12. Schematic band alignments using measured $\Delta E_{\mathrm{V}}$ values and re-

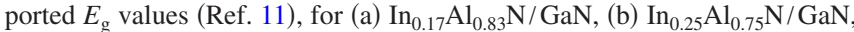
and (c) $\operatorname{In}_{0.30} \mathrm{Al}_{0.70} \mathrm{~N} / \mathrm{GaN}$ interfaces in quasiflat-band situation.

which is a typical value for the XPS measurements of $\Delta E_{\mathrm{V}}{ }^{25-28}$ Even though the evaluated $\Delta E_{\mathrm{V}}$ values were small, the $E_{\mathrm{g}}$ of semiconductors on both sides was much larger than the total error. Therefore, the present results provide important information that $\Delta E_{\mathrm{V}}$ values are small despite the large band gaps of all samples. The measurement of small $\Delta E_{\mathrm{V}}$ values with similar error values can also be found in other reports on $\mathrm{TiO}_{2} / \mathrm{GaN}(0.09 \pm 0.25 \mathrm{eV})$ (Ref. 27) and $\mathrm{HfO}_{2} / \mathrm{GaN}(-0.1 \pm 0.1 \mathrm{eV})$ (Ref. 29) interfaces. As can be seen in Fig. 12, the decrease in $\Delta E_{\mathrm{V}}$ according to the increase in the In molar fraction should have been much smaller than that in $\Delta E_{\mathrm{C}}$. In other words, the change in $E_{\mathrm{g}}$ discontinuity was mostly distributed to that in $\Delta E_{\mathrm{C}}$ at the InAlN/GaN interfaces.

\section{CONCLUSION}

The $\Delta E_{\mathrm{V}}$ of $\operatorname{In}_{0.17} \mathrm{Al}_{0.83} \mathrm{~N} / \mathrm{GaN}, \mathrm{In}_{0.25} \mathrm{Al}_{0.75} \mathrm{~N} / \mathrm{GaN}$, and $\mathrm{In}_{0.30} \mathrm{Al}_{0.70} \mathrm{~N} / \mathrm{GaN}$ heterostructures grown by MOVPE were

TABLE V. $\left(E_{\mathrm{Fsurf}}-E_{\mathrm{Fstab}}\right)$ values for the $\operatorname{InAlN}(2.5 \mathrm{~nm}) / \mathrm{GaN}$ heterostructures in quasiflat-band situation.

\begin{tabular}{lcccc}
\hline \hline & \multicolumn{4}{c}{$\begin{array}{c}E_{\text {Fsurf }}-E_{\text {Fstab }} \\
(\mathrm{eV})\end{array}$} \\
\cline { 2 - 5 } & $\begin{array}{c}\mathrm{In}_{0.17} \mathrm{Al}_{0.83} \mathrm{~N} / \\
\mathrm{GaN}\end{array}$ & $\begin{array}{c}\mathrm{In}_{0.25} \mathrm{Al}_{0.75} \mathrm{~N} / \\
\text { (corrected) }\end{array}$ & \begin{tabular}{c}
$\mathrm{GaN}^{(\text {corrected })}$ \\
\cline { 3 - 5 }
\end{tabular} & $\mathrm{In}_{0.30} \mathrm{Al}_{0.70} \mathrm{~N} / \mathrm{GaN}$ \\
\hline InAlN surface & 0.0 & -0.2 & 0.1 & 0.0 \\
GaN surface & 0.0 & -0.2 & 0.3 & 0.0 \\
\hline \hline
\end{tabular}

evaluated by using XPS. The $E_{\mathrm{CL}}$ and FWHM of the Al $2 p$ increased according to the exit angle, which was explained by band bending due to the polarization-induced electric field in ultrathin InAlN layers combined with surface Fermilevel pinning. The $\Delta E_{\mathrm{V}}$ values evaluated by the conventional method were in disagreement with the theoretical estimates for all samples. The evaluations were therefore corrected by numerical calculations taking into account band bending, which led to the $\Delta E_{\mathrm{V}}$ values being in good agreement with the theoretical estimates for all the interfaces. The evaluated $\Delta E_{\mathrm{V}}$ values were $0.2 \pm 0.2 \mathrm{eV}$ for $\mathrm{In}_{0.17} \mathrm{Al}_{0.83} \mathrm{~N} / \mathrm{GaN}$, $0.1 \pm 0.2 \mathrm{eV}$ for $\operatorname{In}_{0.25} \mathrm{Al}_{0.75} \mathrm{~N} / \mathrm{GaN}$, and $0.0 \pm 0.2 \mathrm{eV}$ for $\operatorname{In}_{0.30} \mathrm{Al}_{0.70} \mathrm{~N} / \mathrm{GaN}$, which indicated that the large change in band-gap discontinuity was mostly distributed to that in $\Delta E_{\mathrm{C}}$.

${ }^{1}$ J. Kuzmik, IEEE Electron Device Lett. 22, 510 (2001).

${ }^{2}$ M. Higashiwaki and T. Matsui, Jpn. J. Appl. Phys., Part 2 43, L768 (2004). ${ }^{3}$ J. Kuzmík, A. Kostopoulos, G. Konstantinidis, J.-F. Carlin, A. Georgakilas, and D. Pogany, IEEE Trans. Electron Devices 53, 422 (2006).

${ }^{4}$ M. Gonschorek, J.-F. Carlin, E. Feltin, M. A. Py, and N. Grandjean, Appl. Phys. Lett. 89, 062106 (2006).

${ }^{5}$ J. Xie, X. Ni, M. Wu, J. H. Leach, Ü. Özgür, and H. Morkoç, Appl. Phys. Lett. 91, 132116 (2007)

${ }^{6}$ M. Hiroki, N. Maeda, and T. Kobayashi, Appl. Phys. Express 1, 111102 (2008).

${ }^{7}$ M. Gonschorek, J.-F. Carlin, E. Feltin, M. A. Py, N. Grandjean, V. Darakchieva, B. Monemar, M. Lorenz, and G. Ramn, J. Appl. Phys. 103, 093714 (2008).

${ }^{8}$ L. Ardaravičius, M. Ramonas, J. Liberis, O. Kiprijanovič, A. Matulionis, J. Xie, M. Wu, J. H. Leach, and H. Morkoç, J. Appl. Phys. 106, 073708 (2009).

${ }^{9}$ O. Ambacher, R. Dimitrov, M. Stutzmann, B. E. Foutz, M. J. Murphy, J. A. Smart, J. R. Shealy, N. G. Weimann, K. Chu, M. Chumbes, B. Green, A. J. Sierakowski, W. J. Schaff, and L. F. Eastman, Phys. Status Solidi B 216, 381 (1999)

${ }^{10}$ C. Ostermaier, G. Pozzovivo, J.-F. Carlin, B. Basnar, W. Schrenk, Y. Douvry, C. Gaquière, J.-C. DeJaeger, K. Čičo, K. Fröhlich, M. Gonschorek, N. Grandjean, G. Strasser, D. Pogany, and J. Kuzmík, IEEE Electron Device Lett. 30, 1030 (2009).

${ }^{11}$ R. E. Jones, R. Broesler, K. M. Yu, J. W. Ager III, E. E. Haller, W. Walukiewicz, X. Chen, and W. J. Schaff, J. Appl. Phys. 104, 123501 (2008).

${ }^{12}$ W. Walukiewicz, S. X. Li, J. Wu, K. M. Yu, J. W. Ager III, E. E. Haller, H. Lu, and W. J. Schaff, J. Cryst. Growth 269, 119 (2004).

${ }^{13}$ M. Akazawa, T. Matsuyama, T. Hashizume, M. Hiroki, S. Yamahata, and N. Shigekawa, Appl. Phys. Lett. 96, 132104 (2010).

${ }^{14}$ J. R. Waldrop and R. W. Grant, Appl. Phys. Lett. 68, 2879 (1996).

${ }^{15}$ D. Briggs and M. P. Seah, Practical Surface Analysis by Auger and X-ray Photoelectron Spectroscopy (Wiley, Sussex, 1983).

${ }^{16}$ Y. Sun, P. Pianetta, P.-T. Chen, M. Kobayashi, Y. Nishi, N. Goel, M. Garner, and W. Tsai, Appl. Phys. Lett. 93, 194103 (2008).

${ }^{17}$ S. Tanuma, C. J. Powell, and D. R. Penn, Surf. Interface Anal. 17, 927 (1991).

${ }^{18}$ S. Tanuma, C. J. Powell, and D. R. Penn, Surf. Interface Anal. 21, 165 (1994).

${ }^{19}$ M. Krawczyk, J. Phys.: Conf. Ser. 100, 042033 (2008)

${ }^{20}$ G. Hollinger, R. Skheyta-Kabbani, and M. Gendry, Phys. Rev. B 49, 11159 (1994)

${ }^{21}$ F. S. Aguirre-Tostado, M. Milojevic, B. Lee, J. Kim, and R. M. Wallace, Appl. Phys. Lett. 93, 172907 (2008).

${ }^{22}$ Y.-J. Lin and C.-T. Lee, Appl. Phys. Lett. 77, 3986 (2000).

${ }^{23}$ P. D. C. King, T. D. Veal, A. Adikimenakis, H. Lu, L. R. Bailey, E. Iliopoulos, A. Georgakilas, W. J. Schaff, and C. F. McConville, Appl. Phys. Lett. 92, 172105 (2008).

${ }^{24}$ W. Walukiewicz, Physica B 302-303, 123 (2001).

${ }^{25}$ G. Martin, A. Botchkarev, A. Rockett, and H. Morkoç, Appl. Phys. Lett. 68, 2541 (1996) 
${ }^{26}$ S. W. King, C. Ronning, R. F. Davis, M. C. Benjamin, and R. J. Nemanich, J. Appl. Phys. 84, 2086 (1998).

${ }^{27}$ P. J. Hansen, V. Vaithyanathan, Y. Wu, T. Mates, S. Heikman, U. K Mishra, R. A. York, D. G. Schlom, and J. S. Speck, J. Vac. Sci. Technol. B 23, 499 (2005).
${ }^{28}$ H. S. Craft, R. Collazo, M. D. Losego, S. Mita, Z. Sitar, and J.-P. Maria, J. Appl. Phys. 102, 074104 (2007).

${ }^{29}$ T. E. Cook, Jr., C. C. Fulton, W. J. Mecouch, R. F. Davis, G. Lucovsky, and R. J. Nemanich, J. Appl. Phys. 94, 7155 (2003). 